\title{
Physician asthma management practices in Canada
}

\author{
Robert Jin MD MHSc ${ }^{1}$, Bernard CK Choi PhD MSc ${ }^{1}$, Benjamin TB Chan MD MPA ${ }^{2}$, \\ Louise McRae BSc ${ }^{1}$, Felix Li MB BS ${ }^{1}$, Lisa Cicutto $\mathrm{PhD}^{3}$, Louis-Philippe Boulet MD ${ }^{4}$, \\ Ian Mitchell $\mathrm{MD}^{5}$, Robert Beveridge $\mathrm{MD}^{6}$, Eric Leith $\mathrm{MD}^{7}$ \\ ${ }^{1}$ Bureau of Cardio-Respiratory Diseases and Diabetes, Laboratory Centre for Disease Control, \\ Health Canada, Ottawa, Ontario (Dr Jin and Dr Li were formerly of the Bureau); \\ 2 Institute for Clinical Evaluative Studies, Toronto, Ontario (formerly of Price Waterhouse); \\ ${ }^{3}$ Canadian Nurses Respiratory Society, Gloucester, Ontario; ${ }^{4}$ Canadian Thoracic Society, \\ Gloucester, Ontario; ${ }^{5}$ Canadian Paediatric Society, Ottawa, Ontario; ${ }^{6}$ Canadian \\ Association of Emergency Physicians, Ottawa, Ontario; ${ }^{7}$ Canadian Society of Allergy and \\ Clinical Immunology, Ottawa, Ontario
}

R Jin, BCK Choi, BTB Chan, et al. Physician asthma management practices in Canada. Can Respir $\mathbf{J}$ 2000;7(6):456-465.

OBJECTIVES: To establish national baseline information on asthma management practices of physicians, to compare the reported practices with the Canadian Consensus recommendations and to identify results potentially useful for interventions that improve physician asthma management practices.

DESIGN: National, stratified cross-sectional survey.

SETTINGS: The 10 provinces and two territories of Canada, from 1996 to 1997.

PARTICIPANTS: Questionnaires were sent to 4489 physicians stratified by province/territory and specialty group (family/general practice, respirology, internal medicine, pediatrics and allergy/immunology); 2605 responses were received.

OUTCOME MEASURES: Methods for the diagnosis, treatment, education and follow-up of patients with asthma ('asthma management practices').

RESULTS: Significant variations existed among the five specialty groups in asthma management practices. A low use of objective measures of airflow limitation to assist with diagnosis was found among some respondents (mostly fam- ily physicians). Up to $40 \%$ of physicians regarded the daily fixed dosing (three or four times a day) of inhaled, short acting beta2-agonist as 'first-line therapy' for moderate to severe asthma. A minority of physicians reported using written action plans for patients or referring them to other health professionals for asthma education. Insufficient time during appointments and a perceived lack of appropriate educational materials were frequently cited as reasons for not providing asthma education. The perceived knowledge of the Canadian Consensus recommendations varied among physicians but was lowest among nonspecialists.

CONCLUSIONS: The survey showed variations in certain aspects of the management of asthma by physicians. The findings will help to target specific areas for future physician education programs and other behavioural change strategies.

Key Words: Asthma; Canadian Asthma Consensus Conference; Clinical practice guidelines; Physicians' practices

\section{Le traitement de l'asthme au Canada}

OBJECTIFS : Établir une base de données nationale sur le traitement de l'asthme afin de mettre en parallèle les mesures

voir page suivante 
thérapeutiques appliquées dans la pratique et les recommandations consensuelles canadiennes, et d'identifier le type d'interventions qui permettraient d'améliorer le traitement de l'asthme dans la pratique.

MODÈLE : Enquête nationale stratifiée, transversale.

CONTEXTE : Les dix provinces et deux territoires du Canada, entre 1996 et 1997.

PARTICIPANTS : Des questionnaires ont été envoyés à 4489 médecins stratifiés par province/territoire et par spécialité (médecine familiale, pratique générale, pneumologie, médecine interne, pédiatrie et allergies/immunologie); 2605 de ces questionnaires ont été retournés.

MESURES PARAMÉTRIQUES : Méthodes diagnostiques, traitement, enseignement, suivi des patients asthmatiques (« la pratique du traitement de l'asthme »).

RÉSULTATS : Des variations significatives ont été notées entre les cinq spécialités quant à leur façon de traiter l'asthme. On a noté une piètre utilisation des mesures objectives de l'obstruction respiratoire comme élément diagnostique chez cer- tains répondants (pour la plupart des médecins de famille). Jusqu'à $40 \%$ des médecins utilisaient en traitement de première intention l'administration quotidienne de doses fixes (trois ou quatre fois par jour) de bêta ${ }_{2}$-agonistes à action brève par inhalation pour l'asthme de modéré à grave. Une minorité de médecins ont déclaré soumettre des plans de traitement écrits à leurs patients ou les adresser à d'autres professionnels de la santé pour un enseignement sur l'asthme. La brièveté des rendez-vous et un manque perçu de matériel didactique approprié ont souvent été invoqués comme raisons pour ne pas faire d'enseignement sur l'asthme. Les médecins ne connaissaient pas tous au même point les recommandations consensuelles canadiennes, mais les connaissances étaient plus partielles chez les non-spécialistes.

CONCLUSION : Cette enquête a révélé que les médecins n'appliquent pas tous avec la même rigueur certains aspects du traitement de l'asthme. Ces conclusions contribueront à identifier les lacunes à combler et les comportements à modifier au moyen de programmes d'éducation médicale continue.
A sthma is a significant public health concern, affecting over two million Canadians (1). Similar to the trends in other Western countries, asthma mortality and hospitalization rates increased significantly during the 1970s and 1980s in Canada (2-4). Because the appropriate management of asthma plays a key role in reducing asthma mortality and morbidity $(5,6)$, and empirical evidence has indicated considerable variation in how physicians manage patients with asthma (7-11), clinical practice guidelines for asthma have been developed in a number of countries, including Canada (12-14). In 1995, in consultation with other medical specialty societies, the Canadian Thoracic Society organized the 'Canadian Asthma Consensus Conference' to develop and publish a set of recommended practices for the management of asthma (14).

With these issues in mind, in 1996 the Laboratory Centre for Disease Control (LCDC), Health Canada, commissioned the first national survey of the asthma management practices of physicians across Canada. The objectives were to establish national baseline information on these practices, to compare the reported practices with those in the Canadian consensus recommendations and to identify suboptimal practices that could be targeted for improvement.

\section{MATERIALS AND METHODS}

The background and methodology of the present study were previously published in the Canadian Respiratory Journal (15). To summarize, five specialty groups of physicians were surveyed: family physicians/general practitioners, respirologists, internists, pediatricians and allergists/clinical immunologists. (A national survey of emergency room physicians had previously been conducted [6], and, therefore, they were not included in the present survey.) The Southam Medical Database was used to determine the number of physicians across Canada in each of the five specialty groups and their respective locations of practice (mailing addresses).

The survey used a pretested, self-administered question- naire designed by experts in clinical medicine, epidemiology and medical education. The questionnaire asked physicians about their general choices of methods for the diagnosis, treatment, education and follow-up of patients with asthma. Physicians were also asked how they would manage three specific clinical patient scenarios (see 'Results' for descriptions of the scenarios). The questionnaire included the demographic characteristics of the respondents and their practices. The questionnaire was completed anonymously.

The survey was mailed in three 'waves' to 4489 physicians in the 10 provinces and two territories of Canada from late 1996 to early 1997 . After the first mailing, a reminder card was sent, followed by a second mailing. To improve response rates further in the third mailing, some physicians were sent an abbreviated version of the questionnaire, designed to be completed in only 5 to $10 \mathrm{~min}$ (versus 10 to $20 \mathrm{~min}$ for the full questionnaire).

\section{RESULTS}

Response rates: Of the 4489 physicians who were sent questionnaires, responses were received from 2605 physicians in the 10 provinces and two territories. Among the respondents, 263 noted that the survey was not applicable to them because they did not treat patients with asthma and 162 questionnaires were unsuitable for analysis, leaving 2180 valid questionnaires. Among them, 1707 were responses to the full version of the questionnaire, while 473 were responses to the abbreviated version. The overall survey response rate was, therefore, 52\% (2180/[4489-263]) for the full and abbreviated questionnaires together, and 40\% (1707/[4489-263]) for the full questionnaire only. The following results are from a combination of the responses to the full and abbreviated questionnaires unless otherwise stated.

Demographic characteristics of the respondents: Some respondents indicated that they belonged to more than one of the five specialty types. Those who indicated an internal medicine subspecialty other than respirology were classified as internists. Physicians who indicated their subspecialty to 
TABLE 1

Demographic characteristics of the respondents by specialty group

\begin{tabular}{|c|c|c|c|c|c|c|}
\hline & Respirology & $\begin{array}{l}\text { Internal } \\
\text { medicine }\end{array}$ & Pediatrics & $\begin{array}{l}\text { Allergy/clinical } \\
\text { immunology }\end{array}$ & $\begin{array}{l}\text { Family } \\
\text { practice }\end{array}$ & All MDs \\
\hline $\begin{array}{l}\text { Sex: \% men, \% women } \\
\quad \text { (total number }{ }^{*} \text { ) }\end{array}$ & $\begin{array}{l}83.7,16.3 \\
(300)\end{array}$ & $\begin{array}{l}86.0,14.0 \\
(236)\end{array}$ & $\begin{array}{l}64.4,35.6 \\
(393)\end{array}$ & $\begin{array}{l}82.7,17.3 \\
\quad(52)\end{array}$ & $\begin{array}{l}74.6,25.4 \\
(1128)\end{array}$ & $\begin{array}{l}75.4,24.6 \\
(2109)\end{array}$ \\
\hline Mean age (years) & 45 & 48 & 47 & 49 & 46 & 46 \\
\hline Years practising (mean) ${ }^{\dagger}$ & 12.2 & 15.5 & 15.3 & 15.8 & 16.8 & 15.7 \\
\hline $\begin{array}{l}\text { Location: \% urban, \% rural } \\
\text { (total number) }\end{array}$ & $\begin{array}{l}97.7,2.3 \\
(306)\end{array}$ & $\begin{array}{l}84.2,15.9 \\
\quad(246)\end{array}$ & $\begin{array}{l}92.6,7.4 \\
(406)\end{array}$ & $\begin{array}{l}98.2,1.9 \\
(54)\end{array}$ & $\begin{array}{l}49.5,50.5 \\
(1148)\end{array}$ & $\begin{array}{l}\text { 69.6, 30.4 } \\
(2160)\end{array}$ \\
\hline
\end{tabular}

${ }^{*}$ Numbers were not the same for identification of sex and urban/rural location because of incomplete responses; ${ }^{\dagger}$ Physicians were asked, "How many years have you been practising in your specialty?"; ' 'Rural' was defined as practising in a community with a population less than 10,000, 'urban' comprises those who did not practise in a rural community; ${ }^{\mathcal{S}}$ Physicians were asked, "How many asthma patients do you see in a month on average?". Numbers and percentages are unweighted. MD Medical doctor

TABLE 2

Methods of asthma diagnosis: Percentages of physicians, by specialty, choosing "almost always" or "often" for patients

\begin{tabular}{|c|c|c|c|c|c|c|c|}
\hline Method of diagnosis & $\begin{array}{l}\text { Respirology } \\
\text { (\%) }\end{array}$ & $\begin{array}{c}\text { Internal } \\
\text { medicine (\%) }\end{array}$ & $\begin{array}{c}\text { Pediatrics } \\
(\%)\end{array}$ & $\begin{array}{l}\text { Allergy/clinical } \\
\text { immunology (\%) }\end{array}$ & $\begin{array}{c}\text { Family practice } \\
\text { (\%) }\end{array}$ & $\begin{array}{l}\text { All MDs } \\
(\%)\end{array}$ & $\mathbf{P}$ \\
\hline \multicolumn{8}{|l|}{$\begin{array}{l}\text { For adults and children over } \\
\text { six years of age }\end{array}$} \\
\hline $\begin{array}{l}\text { Trial course of inhaled } \\
\text { corticosteroids }\end{array}$ & 57.4 & 53.6 & 62.4 & 61.2 & 62.5 & 61.9 & 0.360 \\
\hline Spirometry & 97.9 & 81.0 & 31.1 & 71.3 & 42.7 & 45.4 & $<0.001$ \\
\hline \multicolumn{8}{|l|}{$\begin{array}{l}\text { For children aged six years } \\
\text { and under }\end{array}$} \\
\hline $\begin{array}{l}\text { Trial course of inhaled } \\
\text { beta2-agonists }\end{array}$ & 33.8 & 69.3 & 63.7 & 46.6 & 73.4 & 72.4 & 0.069 \\
\hline Spirometry & 21.3 & 13.8 & 2.4 & 21.1 & 13.6 & 12.7 & 0.012 \\
\hline
\end{tabular}

*May involve the use of spirometry; the questionnaire, however, did not make this choice and the choice of spirometry mutually exclusive. Percentages are weighted. $P$ values from one-way ANOVA indicate whether any statistically significant differences in the percentages exist among the five specialty groups. MD Medical doctor

be pediatrics and respirology, or pediatrics and allergy/immunology were classified as pediatricians.

Table 1 shows the respondents' self-reported characteristics by specialty type, sex, mean age, number of years in practice, urban versus rural location of practice and the average number of patients with asthma seen per month. Most respondents were male physicians; the highest percentage of women was among the pediatricians. The majority of the 'specialists', not surprisingly, practised in urban locations; family physicians, however, were evenly split between urban and rural ('rural' being defined in the survey as a community of fewer than 10,000 people). The difference among the specialty groups in rural compared with urban locations was highly significant $(\mathrm{P}<0.001)$. Mean age and number of years in practice were similar among the five specialty groups. Allergists, respirologists and pediatricians, however, reported seeing considerably more asthma patients per month, on average, than did internists and family physicians.

Methods of diagnosing asthma: Physicians were asked to identify the methods for diagnosing asthma that they used "almost always" or "often" for patients, categorized either as adults and children over six years of age or as children six years of age and under. Although virtually $100 \%$ of respondents said that they used medical history and physical examination (data not shown), percentages varied for the methods of 'objectively measuring' airflow obstruction (Table 2). For adults and children of all ages, a majority of physicians indicated using a trial course of inhaled beta2-agonists or inhaled corticosteroids; a significant minority also chose "response to inhaled beta2-agonists in office or laboratory". Forty-five 
TABLE 3

Treating 'moderate to severe' asthma: Percentages of physicians categorizing drugs as first-line, second-line or third-line maintenance therapy*

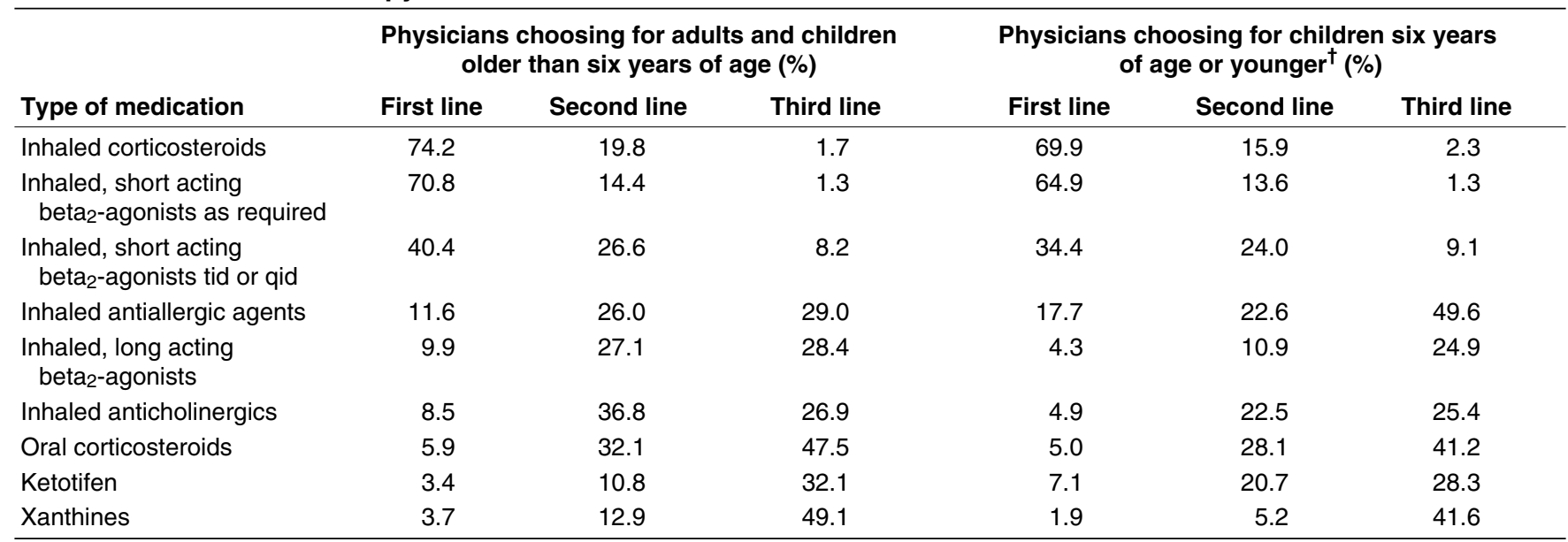

${ }^{*}$ Asked only in the full questionnaire (not the abbreviated version). Respondents were asked to categorize these drugs as first-, second- or third-line maintenance therapy for moderate to severe asthma; ${ }^{\dagger}$ Answered only by those respondents who said that they treated asthmatic children six years of age or younger. Weighted percentages of all respondents are given. Percentages for each medication category do not total $100 \%$ because of nonresponses (ie, not selected as first-, second- or third-line therapy)

per cent of physicians used spirometry for the adults and older children, but only $13 \%$ did so for the younger children. A minority of physicians also used peak expiratory flow (PEF) rate measurement, either at the office or at home, for diagnosing asthma (data not shown).

Among the five specialty groups, there were significant differences $(\mathrm{P}<0.001)$ in choosing the following diagnostic methods: a trial course of inhaled beta2-agonists, response to inhaled beta2-agonists in the office or laboratory, and spirometry. Most family physicians used a trial course of inhaled beta2-agonists, while fewer respirologists did so. Respirologists and internists reported using spirometry more often than did family practitioners and pediatricians. For children six years of age or younger, there was a significant interspecialty difference in using spirometry $(\mathrm{P}=0.012)$, with $2.4 \%$ of pediatricians choosing this method to diagnose asthma.

Prescribing medications for the treatment of asthma: Physicians were asked to categorize asthma medications as 'first line', 'second line' or 'third line' in the maintenance treatment of patients with 'moderate to severe asthma' (ie, excluding persons with 'intermittent, brief symptoms'). Over $70 \%$ of physicians considered inhaled corticosteroids and the 'as required' use of inhaled, short acting beta2-agonists as 'first-line therapy' for adults and children (Table 3). Forty per cent of all respondents considered the regular use (three or four times a day) of inhaled, short acting beta2-agonists to be 'first-line therapy' for adults and children over six years of age, and $34.4 \%$ of physicians considered it so for younger children.

Approximately $12 \%$ of physicians regarded inhaled antiallergic agents (such as cromolyn sodium) as 'first-line' maintenance therapy for adults and children over six years of age; approximately $18 \%$ and $7 \%$ considered antiallergic agents and ketotifen, respectively, as 'first line' for younger children.
For the other drug categories, the majority of respondents considered them to be either 'second line' or 'third line' (Table 3).

Management of clinical scenarios: Physicians were asked about their choices of investigations and treatments for managing three clinical scenarios. Tables 4, 5 and 6 compare the results for all of the respondents with those of the respirologists alone. (Due to space constraints, the results for the other four specialty groups are not shown but are available on request from the authors.)

Scenario 1: The first scenario was described as follows:
A 17-year-old female patient of yours with a several- year history of asthma presents with difficulty breath- ing, increased coughing and disrupted sleep over the past week. In response to symptoms, she has been using her inhaled, short acting $\beta_{2}$-agonist four times a day. She takes no other medications. In general, she has few asthma symptoms except in the fall when her exacerba- tions lead her to miss days from school. It is now late September. On examination, there is wheezing and a slightly prolonged expiratory phase. Her pulse is 100, her colour is good, and she has no fever.

The majority of respirologists $(91.7 \%)$ reported that they would use spirometry to investigate this patient compared with $43.5 \%$ of all respondents (all five specialty groups, including the respirologists) (Table 4). Collectively, physicians were most inclined to measure PEF at the office visit. Respirologists were less likely than physicians overall to order a chest X-ray and a complete blood count for the patient.

With regard to treatment choices, there was considerable variation in the responses. Most respirologists (61\%) would start the patient on high dose, inhaled corticosteroids, whereas physicians overall (58\%) were more inclined to 
TABLE 4

Scenario 1*: Percentage of respirologists compared with all physicians ordering various investigations and treatments

\begin{tabular}{|c|c|c|}
\hline & $\begin{array}{l}\text { All MDs } \\
(\%)\end{array}$ & $\begin{array}{c}\text { Respirologists } \\
\text { (\%) }\end{array}$ \\
\hline \multicolumn{3}{|l|}{ Investigations } \\
\hline Peak expiratory flow at office visit & 63.7 & 29.8 \\
\hline Spirometry in office or laboratory & 43.5 & 91.7 \\
\hline $\begin{array}{l}\text { Ask patient to monitor peak expiratory } \\
\text { flow at home }\end{array}$ & 38.8 & 30.5 \\
\hline Chest x-ray & 28.2 & 12.1 \\
\hline Complete blood count & 20.1 & 10.0 \\
\hline Lung volumes/diffusing capacity & 5.0 & 6.0 \\
\hline \multicolumn{3}{|l|}{ Treatment - Types of drugs } \\
\hline \multicolumn{3}{|l|}{ Beta 2 -agonists } \\
\hline Increase dose inhaled, short acting & 28.4 & 14.6 \\
\hline Same dose inhaled, short acting & 58.4 & 49.0 \\
\hline Decrease dose inhaled, short acting & 7.7 & 21.6 \\
\hline Inhaled, long acting & 7.9 & 8.9 \\
\hline Oral beta2-agonist & 1.3 & 0.4 \\
\hline \multicolumn{3}{|l|}{ Corticosteroids } \\
\hline Inhaled, low dose ${ }^{\dagger}$ & 57.9 & 31.1 \\
\hline Inhaled, high dose ${ }^{\ddagger}$ & 38.1 & 61.0 \\
\hline Oral corticosteroid & 17.1 & 23.6 \\
\hline \multicolumn{3}{|l|}{ Others } \\
\hline Inhaled anticholinergics & 14.2 & 2.4 \\
\hline Inhaled antiallergic agents & 11.1 & 2.0 \\
\hline Antihistamines & 6.8 & 0.6 \\
\hline Antibiotics & 6.7 & 2.2 \\
\hline Allergy shots & 4.6 & 0.3 \\
\hline Xanthines & 3.5 & 2.1 \\
\hline \multicolumn{3}{|l|}{ Method of administering drugs } \\
\hline MDI with spacer & 40.9 & 30.9 \\
\hline MDI alone & 21.9 & 15.2 \\
\hline Turbuhaler & 21.4 & 43.9 \\
\hline MDI with spacer and mask & 3.2 & 1.3 \\
\hline Wet nebulizer & 1.8 & 0 \\
\hline Diskhaler & 1.2 & 0.3 \\
\hline Missing responses & 9.6 & 8.5 \\
\hline \multicolumn{3}{|c|}{$\begin{array}{l}\text { “See text for description of the first clinical scenario in the survey. ‘'Low } \\
\text { dose' inhaled corticosteroid was defined as daily dosages of } 800 \mu \mathrm{g} \text { or } \\
\text { less of beclomethasone or budesonide, or } 500 \mu \mathrm{g} \text { or less of fluticasone; } \\
\text { ‘'High dose' inhaled corticosteroid was defined as greater than the } \\
\text { above dosages. MDI Metered dose inhaler (ie, freon-propelled, pressur- } \\
\text { ized MDI, as distinguished from the Turbuhaler; the questionnaire, how- } \\
\text { ever, did not specify this distinction) }\end{array}$} \\
\hline
\end{tabular}

start low dose, inhaled steroids (Table 4; see table footnote for the definition of 'high' and 'low' dose). In terms of the patient's inhaled, short acting beta2-agonist, the most popular response of both respirologists and physicians overall was to maintain the same dose; the second most common response among the respirologists was to lower the patient's dose, whereas among physicians overall, it was to raise the dose.

Compared with physicians overall, very few respirologists selected other types of drugs for this patient, such as an inhaled anticholinergic (eg, ipratropium bromide) or antiallergic agent (eg, cromolyn sodium) (Table 4). In terms of the
TABLE 5

Scenario 2*: Percentage of respirologists compared with all physicians ordering various treatments

\begin{tabular}{lcc}
\hline Drug treatment & $\begin{array}{c}\text { All MDs } \\
(\%)\end{array}$ & $\begin{array}{c}\text { Respirologists } \\
(\%)\end{array}$ \\
\hline $\begin{array}{l}\text { Beta2-agonists } \\
\text { Inhaled, short acting, maintain }\end{array}$ & 53.6 & 47.6 \\
$\quad$ same dose & & \\
$\quad$ Inhaled, short acting, decrease & 17.0 & 17.3 \\
$\quad$ dose & & \\
$\quad$ Inhaled, short acting, increase & 14.5 & 11.6 \\
$\quad$ dose & & \\
Inhaled, long-acting & 16.8 & 20.8 \\
$\quad$ Oral beta2-agonist & 1.5 & 0.7 \\
Corticosteroids & & \\
Oral corticosteroid & 83.5 & 95.4 \\
$\quad$ Inhaled, maintain same dose & 27.4 & 18.9 \\
Inhaled, increase dose & 21.1 & 18.2 \\
$\quad$ Inhaled, decrease dose & 4.2 & 0.8 \\
Others & & \\
Inhaled anticholinergics & 28.5 & 11.4 \\
Antibiotics & 12.9 & 2.0 \\
$\quad$ Xanthines & 12.6 & 6.2 \\
Inhaled antiallergic agents & 7.9 & 2.4 \\
Allergy shots & 2.9 & 0 \\
Antihistamines & 2.6 & 0 \\
\hline
\end{tabular}

${ }^{*}$ See text for description of the second clinical scenario in the survey. MD Medical doctor

methods of administering the drugs, respirologists chose the metered-dose inhaler (MDI), alone or with a spacer, with approximately equal frequency as a Turbuhaler (Pulmicort Turbuhaler, AstraZeneca Canada Inc). However, collectively, physicians most frequently chose the MDI with spacer (41\%); MDI alone and the Turbuhaler were, respectively, distant second and third choices.

Scenario 2: The second scenario also concerned a young adult but with a more severe exacerbation of asthma:

An 18-year-old male asthma patient of yours presents with continuous asthma symptoms and frequent episodes of disrupted sleep over the past two weeks. While on vacation last week, he presented himself to the emergency department with an asthma exacerbation. According to the emergency department physician, his peak flow rate was $60 \%$ of predicted for his age and height. For the past week, he has been using an inhaled $\beta_{2}$-agonist more than four times a day, which brings him incomplete relief, and inhaled corticosteroid four times a day (beclomethasone $1500 \mathrm{mcg} /$ day). His current peak expiratory flow rate is $58 \%$ of his personal best. He is taking no other medications.

For this scenario, the questionnaire asked only about treatment. The majority of all respondents (about 83.5\%) said they would start oral corticosteroid (prednisone), and this predilection was even stronger among respirologists $(95.4 \%)$ (Table 5). Approximately half (53.6\%) of all respondents 
would maintain the dose of inhaled, short acting beta2-agonist, and there was a similar response by the respirologists (47.6\%). Similar percentages of both groups would also start an inhaled, long acting beta2-agonist such as salmeterol. As in scenario 1, only small percentages of respirologists chose other types of drugs. Among physicians overall, $28.5 \%$ selected inhaled anticholinergics, and about $13 \%$ chose antibiotics or xanthines for the patient.

Scenario 3: The third scenario described a young child with symptoms suggestive of early asthma, as yet undiagnosed:

Susan is a 4-year-old girl who visited your office two months ago with symptoms of a cold. Since that time, her mother has noticed that the cough has persisted and is worse at night, and that she has difficulty breathing when running in the playground. She is otherwise healthy. Physical examination is unremarkable. Chest $x$-ray and neutrophil count are normal.

To investigate this patient, physicians chose a variety of diagnostic methods; the most popular choice overall was a trial course of inhaled beta2-agonist (64\%). Respirologists, however, were more likely to try a course of inhaled corticosteroid (58.4\%) (Table 6). Other methods chosen were beta2-agonist trial in the office or laboratory, allergy testing and provocational testing (eg, methacholine challenge).

To treat this child, $90 \%$ of the respirologists compared with $68 \%$ of physicians overall would use an inhaled, short acting beta2-agonist as required. About three-quarters of all physicians would start an inhaled, 'low pediatric dose' corticosteroid, as would $54 \%$ of respirologists (Table 6; see table footnote for the definition of 'high' and 'low' dose). Respirologists were more inclined to start a 'high pediatric dose' corticosteroid than physicians collectively. Similar percentages (17\% to $18 \%$ ) would prescribe an inhaled antiallergic agent. With regard to the mode of administering treatment, most respirologists would use an MDI with spacer, whereas physicians overall were almost equally as likely to order a mask with the spacer and MDI.

Providing education to patients: Physicians were asked whether they agreed or disagreed with the statement, "I believe I am providing enough asthma information to my patients". Most respondents agreed (68.5\%), and $17.0 \%$ strongly agreed. Only $14.8 \%$ disagreed or strongly disagreed. There was little difference among the specialty groups: $96 \%$ of internists, $91 \%$ of allergists, $90 \%$ of pediatricians, $85 \%$ of respirologists and $84 \%$ of family doctors thought that they were providing enough asthma information to patients ("agreed" or "strongly agreed").

Physicians were asked whether they engaged in specific kinds of educational actions for their patients with asthma (Table 7). Most physicians (85\% to $94 \%$ ) indicated that they discussed the following topics with "all" or "most" of their patients: information on medications, environmental control measures and avoidance of triggers, warning signs and symptoms of worsening asthma, actions to take when
TABLE 6

Scenario $3^{\star}$ : Percentage of respirologists compared with all physicians ordering various investigations and treatments

\begin{tabular}{|c|c|c|}
\hline & $\begin{array}{c}\text { All MDs } \\
(\%)\end{array}$ & $\begin{array}{c}\text { Respirologists } \\
(\%)\end{array}$ \\
\hline \multicolumn{3}{|l|}{ Investigations } \\
\hline Trial course inhaled beta 2 -agonist & 64.1 & 50.6 \\
\hline Trial course inhaled corticosteroid & 41.9 & 58.4 \\
\hline Beta 2 -agonist in office or laboratory & 30.0 & 32.4 \\
\hline Allergy testing & 14.7 & 27.4 \\
\hline Provocational test & 7.3 & 13.1 \\
\hline \multicolumn{3}{|l|}{ Treatment - Types of drugs } \\
\hline \multicolumn{3}{|l|}{ Beta2-agonists } \\
\hline Inhaled, short acting as required & 68.0 & 90.3 \\
\hline Inhaled, short acting tid or qid & 18.9 & 3.4 \\
\hline Oral, short acting & 4.6 & 3.4 \\
\hline Inhaled, long acting & 1.6 & 0 \\
\hline \multicolumn{3}{|l|}{ Corticosteroids } \\
\hline Inhaled, low pediatric dose ${ }^{\dagger}$ & 74.0 & 54.2 \\
\hline Inhaled, high pediatric dose $\mathrm{e}^{\ddagger}$ & 10.6 & 28.8 \\
\hline Oral pediatric dose & 1.8 & 3.5 \\
\hline \multicolumn{3}{|l|}{ Others } \\
\hline Inhaled antiallergic agents & 16.9 & 17.5 \\
\hline Ketotifen & 8.4 & 6.9 \\
\hline Inhaled anticholinergics & 2.5 & 0 \\
\hline Antihistamines & 2.1 & 0 \\
\hline Allergy shots & 1.6 & 0 \\
\hline Antibiotics & 1.5 & 0 \\
\hline \multicolumn{3}{|l|}{ Method of administering drugs } \\
\hline MDI with spacer & 41.0 & 56.2 \\
\hline MDI with spacer and mask & 39.8 & 25.4 \\
\hline MDI alone & 2.3 & 0 \\
\hline Turbuhaler & 2.0 & 5.0 \\
\hline Wet nebulizer & 1.9 & 0 \\
\hline Diskhaler & 0.6 & 2.3 \\
\hline Missing responses & 12.4 & 11.1 \\
\hline
\end{tabular}

* See text for description of the third clinical scenario in the survey;

t'Low pediatric dose' was defined as equivalent to daily dosages of fluticasone $250 \mu \mathrm{g}$ or less, or beclomethasone $200 \mu \mathrm{g}$ or less; ¥'High dose' was defined as greater than the above dosages. MD Medical doctor; MDI Metered dose inhaler

the asthma worsens and indications for seeking emergency medical care (data not shown). Fifty-eight per cent of physicians stated that they asked patients to demonstrate inhaler technique. Thirty-seven per cent of physicians reported providing educational pamphlets, brochures, booklets or videos about asthma. Only 17\%, however, mentioned developing a written action plan for patients. A similarly small percentage would refer patients to a nurse, another health professional, an asthma centre, a hospital or a nonprofit agency for the purpose of asthma education.

There were statistically significant interspecialty differences. With the exception of providing educational materials, greater percentages of respirologists, pediatricians, allergists and internists reported carrying out these educational actions than did family doctors (Table 7). 
TABLE 7

Percentage of physicians, by specialty, stating provision of educational actions for "all” or "most" asthma patients*

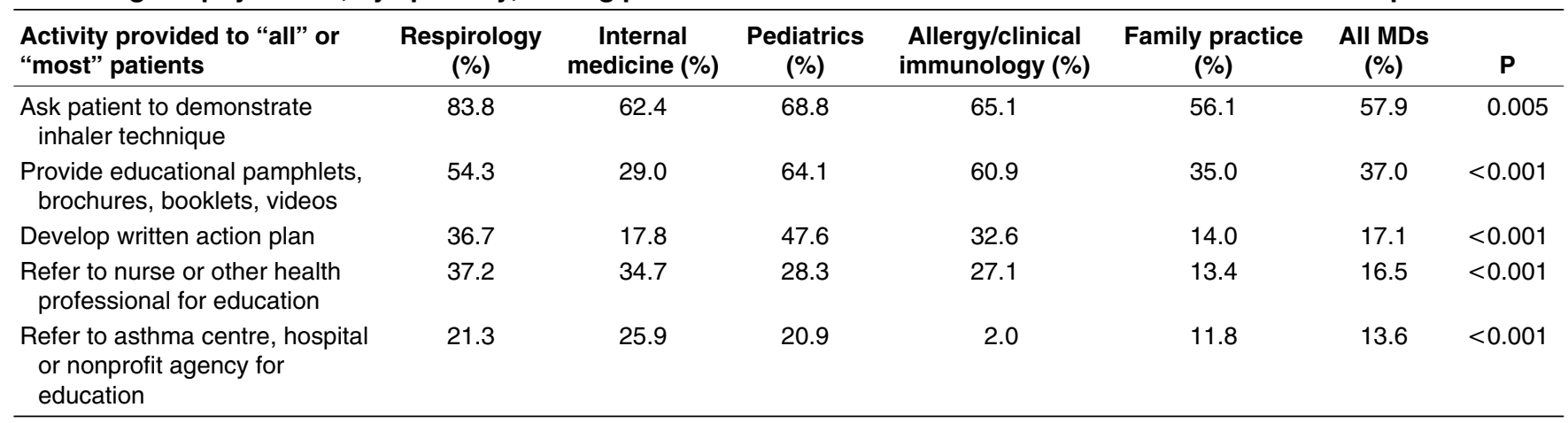

*Question was asked only in the full questionnaire (not the abbreviated version). Weighted percentages are given. $P$ values from one-way ANOVA indicate whether statistically significant differences existed among the five specialty groups. MD Medical doctor

TABLE 8

Percentage of physicians, by specialty, stating reasons for not providing enough asthma education to patients

\begin{tabular}{|c|c|c|c|c|c|c|}
\hline Reasons offered in questionnaire* & $\begin{array}{l}\text { Respirology } \\
\text { (\%) }\end{array}$ & $\begin{array}{l}\text { Internal medicine } \\
(\%)\end{array}$ & $\begin{array}{l}\text { Pediatrics } \\
\text { (\%) }\end{array}$ & $\begin{array}{l}\text { Allergy/clinical } \\
\text { immunology (\%) }\end{array}$ & $\begin{array}{c}\text { Family practice } \\
(\%)\end{array}$ & $\begin{array}{l}\text { All MDs } \\
(\%)\end{array}$ \\
\hline Not enough time during appointments & 49.1 & 35.6 & 44.3 & 33.5 & 36.1 & 36.5 \\
\hline $\begin{array}{l}\text { No appropriate materials available to } \\
\text { use }\end{array}$ & 11.6 & 32.1 & 12.1 & 11.2 & 36.4 & 34.9 \\
\hline No community resources & 27.9 & 26.9 & 16.1 & 9.3 & 33.6 & 32.4 \\
\hline It takes too much time & 38.5 & 20.7 & 32.9 & 41.0 & 23.2 & 23.7 \\
\hline $\begin{array}{l}\text { Costs of materials to patients are } \\
\text { prohibitive }\end{array}$ & 8.1 & 11.8 & 7.6 & 3.7 & 8.0 & 8.2 \\
\hline Other reasons given & 14.1 & 26.1 & 27.8 & 9.3 & 21.9 & 22.3 \\
\hline
\end{tabular}

${ }^{*}$ Respondents could check off one or more listed reasons and/or provide their own reasons (last category). Weighted percentages are given. Using one-way ANOVA, the only significant difference among the specialty groups was for the reason "no appropriate (educational) materials available to use" $(P=0.009)$. MD Medical doctor

Physicians were then asked to choose, from a list of possibilities, their reasons for not providing enough asthma education to patients (Table 8). Although only 325 of 2180 (14.8\%) physicians indicated that they were "not providing enough asthma information" to patients (data not shown), 800 still responded to the question asking them to select the possible reasons for not providing enough asthma education to patients (Table 8).

The most common reasons offered by physicians for not providing enough asthma education to patients were "not enough time during appointments" (36.5\%), "no appropriate materials available for use" $(34.9 \%)$ and "no community resources" (32.4\%) (Table 8). "It takes too much time" was cited by $23.7 \%$ of the respondents; other reasons given were "patients are not receptive", "not trained to do it" and "cost of materials to patients are prohibitive".

Reported knowledge of the Canadian Consensus recommendations: When physicians were asked whether they were "aware of", had "looked at" or were "knowledgeable about" the Canadian Asthma Consensus recommendations ('practice guidelines') (13), 66.3\%, 57.1\% and $41.3 \%$, respectively, answered in the affirmative (Table 9). Respi- rologists had the highest proportions of positive responses, followed by allergists, pediatricians, internists and family practitioners; $37.5 \%$ of family physicians indicated that they were "knowledgeable about" the guidelines.

Logistic regression analysis was used to ascertain whether physicians who stated that they were "knowledgeable about" the recommendations were more or less likely to choose certain asthma management practices (ie, a correlation of selfreported knowledge with self-reported behaviour). Highly statistically significant associations $(\mathrm{P}<0.001)$ were found for developing a written action plan for "all" or "most" patients, using PEF at home "almost always" or "often" for follow-up of patients, having the patient in scenario 1 monitor her PEF at home, and providing educational materials to "all" or "most" patients (data not shown). Physicians who indicated that they were "guideline-knowledgeable" were less likely to use PEF at home or office "almost always" or "often" for diagnosing asthma in adults and children older than six years of age $(\mathrm{P}<0.001)$.

\section{DISCUSSION}

Variations in physicians' practices: The survey revealed deviations in asthma management approaches recommended 
TABLE 9

Physicians' self-reported awareness of the 'practice guidelines'*

\begin{tabular}{|c|c|c|c|c|c|c|c|}
\hline Responded “yes" to: & $\begin{array}{c}\text { Respirology } \\
\text { (\%) }\end{array}$ & $\begin{array}{c}\text { Internal medicine } \\
(\%)\end{array}$ & $\begin{array}{l}\text { Pediatrics } \\
\text { (\%) }\end{array}$ & $\begin{array}{l}\text { Allergy/clinical } \\
\text { immunology (\%) }\end{array}$ & $\begin{array}{c}\text { Family practice } \\
\text { (\%) }\end{array}$ & $\begin{array}{c}\text { All MDs } \\
(\%)\end{array}$ & $\mathbf{P}$ \\
\hline "Aware of" the guidelines? & 98.1 & 64.8 & 84.9 & 93.1 & 64.2 & 66.3 & $<0.001$ \\
\hline "Looked at" the guidelines? & 93.8 & 57.4 & 78.1 & 91.4 & 54.5 & 57.1 & $<0.001$ \\
\hline $\begin{array}{l}\text { "Knowledgeable about" the } \\
\text { guidelines? }\end{array}$ & 91.8 & 43.3 & 69.8 & 86.3 & 37.5 & 41.3 & $<0.001$ \\
\hline
\end{tabular}

*Guidelines were defined as being the Canadian Asthma Consensus Conference recommendations (14). The question was asked only in the full questionnaire (not the abbreviated version). Percentages are weighted. P values from one-way ANOVA indicate whether statistically significant differences existed among the five specialty groups. MD Medical doctor

by the Canadian Consensus guidelines. Statistically significant differences were also found among the five physician specialties.

Variations in diagnosing asthma: According to the Consensus guidelines, objective measures of airflow limitation are recommended for diagnosing asthma in adults and children who are capable of giving 'a good test'. Spirometry is the preferred method, but PEF monitoring may also be used. Very large percentages of internists, allergists and especially respirologists (98\%) reported using spirometry "almost always" or "often", but lower percentages of pediatricians and family physicians reported the same. There are several possible reasons for this variation. Physicians who see more patients with asthma or asthma-like conditions are likely to be more familiar with the uses of spirometry or PEF monitoring. These physicians are more likely to have the equipment in their offices or clinics, or to know when and where to refer patients for such testing.

In addition, young children (eg, younger than five or six years of age) are less likely to achieve reliable results in performing spirometry because of insufficient understanding or physical coordination. The survey results suggest that this is perceived by most physicians; using spirometry "almost always" or "often" for this age group was reported by about $13 \%$ of physicians overall and by only $2.4 \%$ of pediatricians. Moreover, the lower percentage of pediatricians (31\%) reporting use of spirometry in adults and children over six years of age may simply reflect the fact that pediatricians see more younger children than do the other specialists; therefore, spirometry is not ordered 'almost always' or 'often'. Variations in the methods of treatment: Perhaps the most significant deviation from the Consensus recommendations was the regular use of inhaled, short acting beta2-agonists. Forty per cent of all physicians responded that the regular use of inhaled, short acting beta2-agonists, three or four times daily, would be 'first-line therapy' for adults and children over six years of age, and one-third of physicians considered it to be first-line therapy for younger children. The guidelines advise that patients receive preventive/maintenance therapy with regular anti-inflammatory medication (primarily inhaled corticosteroids) in sufficient doses to minimize the need for inhaled, short acting beta2-agonists. Short acting beta2-agonists should be used on an 'as needed' basis only for the relief of acute symptoms or attacks, or in immediate anticipation of exposure to 'triggers' such as allergens or exercise.
There was widespread agreement among physicians that both inhaled corticosteroids and inhaled, short acting beta2-agonists (taken 'as required') comprise 'first-line' maintenance therapy for adults and children with moderate to severe asthma, which is consistent with the recommendations. The majority of physicians also appropriately considered inhaled anticholinergics; inhaled, long acting beta2-agonists; and xanthines (eg, theophylline) to be 'second-' or 'third-line therapy'. Less appropriate, according to the recommendations, was the tendency of most physicians to regard oral corticosteroids as 'third line' when these should be considered 'second-line' treatment for moderate to severe asthma exacerbations.

In the clinical scenarios, a minority of physicians also inappropriately selected a long acting beta2-agonist (eg, salmeterol) for managing an acute exacerbation of asthma, although such a medication should only be used for achieving longer term control of chronic asthma.

Variations in the education of patients: While nearly half of all the respirologists reported developing written action plans for "all" or "most" of their patients, smaller percentages of family doctors and internists reported doing so. Action plans have been considered an important component of asthma management since the first consensus conference in 1989. This finding might reflect a lack of awareness about the benefit of individualized action plans. All patients, except those with very mild, stable symptoms, should have action plans. On the other hand, fewer family physicians may develop written action plans because more of their patients have very mild asthma or because they may have already received such a plan from a specialist.

There were also significant differences in the proportions of physicians among the specialty groups who used educational resources for patients (pamphlets, booklets, videos) and who referred patients to other professionals for asthma education (nurses, other health professionals, asthma centres, hospitals or nonprofit agencies). Lower percentages of internists and family doctors reported using educational materials, and a smaller percentage of family physicians reported that they referred patients to other professionals for education.

Barriers to educating patients: The survey found that these practices were reflected in the perceptions of some physicians. Two of the more commonly cited 'barriers' to educating patients were "no appropriate materials available to 
use" and "no community resources". Family doctors and internists were more likely to choose the former reason, and family physicians were somewhat more likely than were the other specialists to choose the latter reason as well.

These findings suggest that physicians need to be more aware of the abundance of educational materials that are available, for example, from nonprofit organizations, medical associations and pharmaceutical companies, as well as from the other health professionals and agencies to whom patients can be referred. On the other hand, it is possible that most physicians are aware of these resources in their communities, but some feel that these resources are not easily accessible or suitable (in the case of educational materials) for their patients.

Finding the best means of improving access to, or suitability of, such educational resources for patients is a critical issue because the 'barrier to educating patients' most frequently cited in the survey was the combination of "not enough time during appointments" and "it [educating patients] takes too much time".

Knowledge about the guidelines: The levels of "awareness" and "knowledge" of the Canadian Consensus recommendations by the five specialty groups in the survey assessed the relative success of the implementation of the 1995 Consensus guidelines. While a majority of each specialty group self-reported being "aware" of the recommendations, there were statistically significant differences among the groups. Only $37.5 \%$ of family practitioners and $43 \%$ of internists felt that they were "knowledgeable about" the recommendations. This suggests that these guidelines were not adequately disseminated to, or read by, a significant proportion of physicians in Canada.

The present survey found some associations between an increased awareness and knowledge of the recommendations and appropriate practices, such as developing written action plans for patients, providing educational materials, and using home PEF for monitoring or following-up patients. This observation deserves further study to determine whether interventions to increase physicians' knowledge of the guidelines would lead to improved asthma management practices (ie, a 'cause-and-effect relationship'). Given the cross-sectional nature of this survey, one can only conclude that there were some statistically significant associations.

\section{LIMITATIONS OF THE SURVEY}

The limitations of the present study are typical of those involving mailed, self-administered questionnaires (15). The respondents might have been physicians who frequently manage asthma patients or have a particular interest in asthma. If so, the actual nature of medical asthma management in Canada deviates more from the Consensus recommendations than was found by the present survey. The respondents might also have been physicians who tend to answer mailed questionnaires; the implication of this bias in terms of asthma management practices is unknown. Finally, in terms of possible self-reporting bias, the survey responses may not have necessarily reflected the actual practices of these physicians.

\section{RECOMMENDATIONS}

This national survey observed specific asthma management practices (diagnosis, treatment, education and followup) that were not consistent with the 1995 Canadian Consensus recommendations. Consequently, medical education programs or other behavioural change interventions are recommended to address these inconsistencies. The results of the survey also indicate the specialty groups of physicians to which interventions may be targeted concerning specific areas of asthma management.

Before publication, the results of this survey were shared with the medical and other health organizations partnered with the LCDC on the National Asthma Control Task Force and the Canadian Network for Asthma Care. Knowledge of the survey findings has been valuable to these organizations because key individuals in these groups were leaders in both the original Canadian Asthma Consensus Conference (1995) and the recent update of these recommendations (1999) (16). Another national survey in two or three years is recommended for the evaluation of the success of the implementation (dissemination and uptake) of the 1999 Consensus guidelines.

ACKNOWLEDGEMENTS: The authors thank the following individuals for their assistance in the development, conduct and/or analysis of the Physician Asthma Management Study: Bill Hayes, Les Teichroew and Janet Whittall (Price Waterhouse); Dr Gregory Taylor (Director, Bureau of Cardio-Respiratory Diseases and Diabetes, LCDC); Dr Charles Mustard (former Chief, Respiratory Disease Division, LCDC); Dr Mervyn Dean (The College of Family Physicians of Canada); and Dr Frank Mo (former consultant to the Respiratory Disease Division, LCDC).

\section{REFERENCES}

1. Statistics Canada. National Population Health Survey, 1996-97 (Health Share File). Ottawa: Statistics Canada, 1998 (unpublished tabulations).

2. Mao Y, Semenciw R, Morrison H, MacWilliam L, Davies J, Wigle D. Increased rates of illness and death from asthma in Canada. CMAJ 1987;137:620-4.

3. Hogg RS, Schechter MT, Montaner JSG, Hogg JC. Asthma mortality in Canada, 1946-1990. Can Respir J 1995;2:61-6.

4. Wilkins K, Mao Y. Trends in rates of admission to hospital and death from asthma among children and young adults in Canada during the 1980s. CMAJ 1993;148:185-90.

5. Garrett J, Kolbe J, Richards G, Whitlock T, Rea H. Major reduction in asthma morbidity and continued reduction in asthma mortality in New Zealand: what lessons have been learned? Thorax 1995;50:303-11

6. Cockcroft DW. Management of acute severe asthma. Ann Allergy Asthma Immunol 1995;75:83-93.

7. Grunfeld A, Beveridge RC, Berkowitz J, FitzGerald JM. Management of acute asthma in Canada: an assessment of emergency physician behaviour. J Emerg Med 1997;15:547-56.

8. Engel W, Freund DA, Stein JS, Fletcher RH. The treatment of patients with asthma by specialists and generalists. Med Care 1989;27:306-14.

9. Neville RG, Clark RC, Hoskins G, Smith B, for the General Practitioners in Asthma Group. National asthma attack audit 1991-2. BMJ 1993;306:559-62.

10. Phin S, Oates RK. Variations in the treatment of childhood asthma. Med J Aust 1993;159:662-6. 
11. Epton MJ, Skidmore C, O’Hagan JJ, Curry C, Wood-Baker R, Town GI. An audit and international comparison of asthma management in the emergency department. N Z Med J 1994;107:26-9.

12. Hargreave FE, Dolovich J, Newhouse MT. The assessment and treatment of asthma: A conference report. J Allergy Clin Immunol 1990;85:1098-111.

13. NHLBI (National Heart, Lung and Blood Institute). International consensus report on diagnosis and management of asthma. Clin Exp Allergy 1992;22(Suppl 1):1-72.
14. Ernst P, Fitzgerald JM, Spier S. Canadian Asthma Consensus Conference: Summary of Recommendations. Can Respir J 1996;3:89-100.

15. Jin RL, Choi BCK. The 1996 and 1997 National Survey of Physician Asthma Management Practices: Background and study methodology. Can Respir J 1999;6:269-72.

16. Boulet LP, Becker A, Berube D, Beveridge R, Ernst P, on behalf of the Canadian Asthma Consensus Group. Canadian Asthma Consensus Report, 1999. CMAJ 1999;161(11 Suppl):S1-61. 


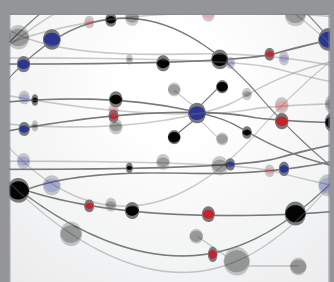

The Scientific World Journal
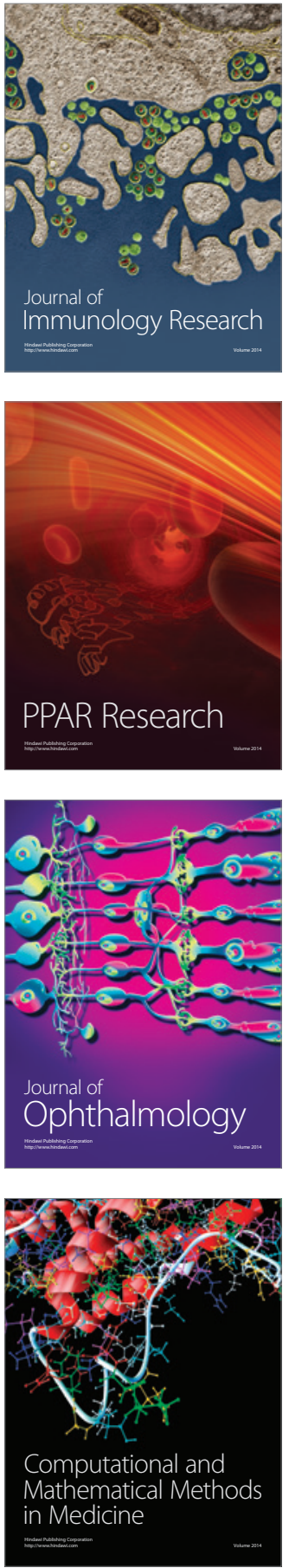

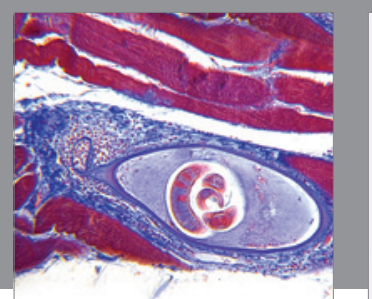

Gastroenterology Research and Practice

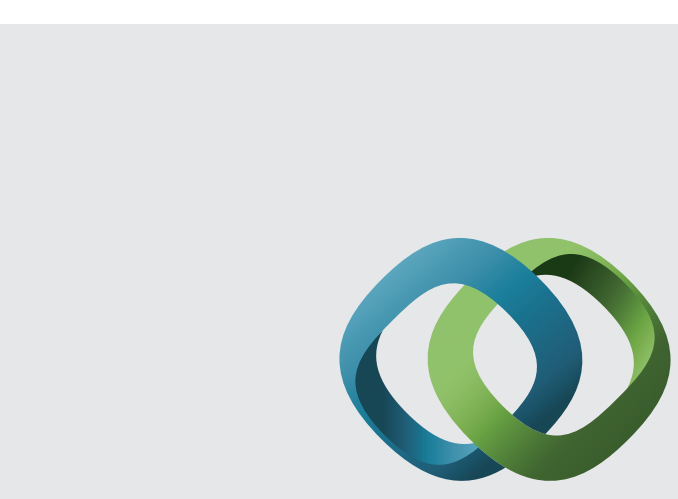

\section{Hindawi}

Submit your manuscripts at

http://www.hindawi.com
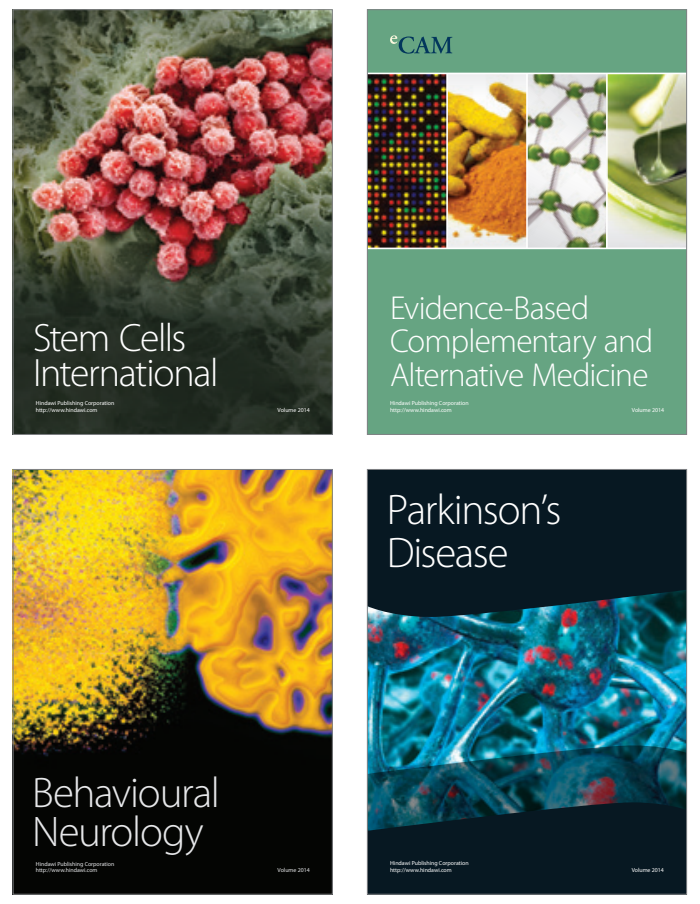
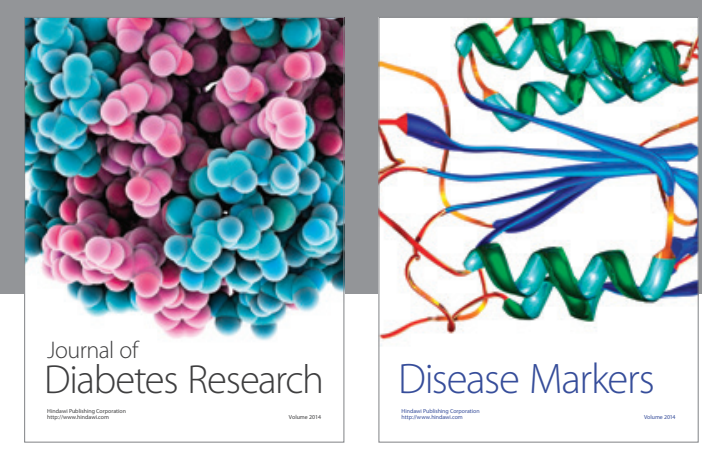

Disease Markers
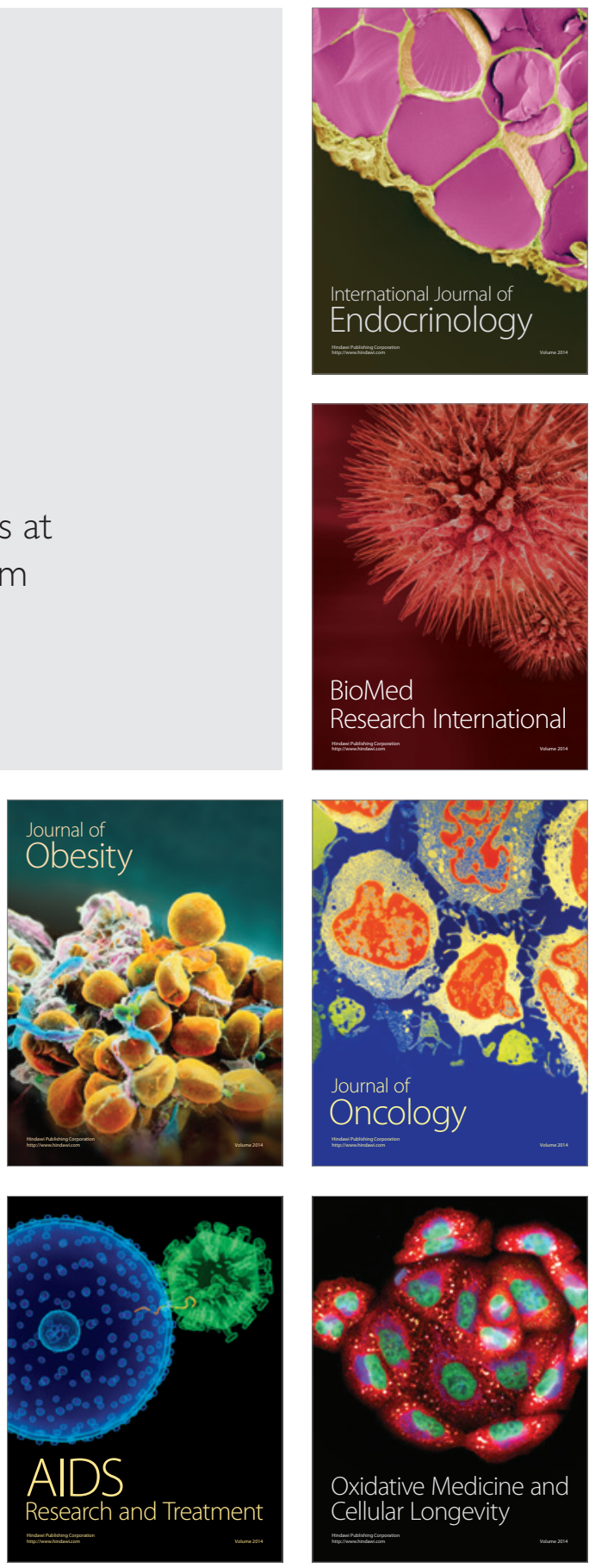